\title{
As articulações entre intimidade e trabalho: a construção social de um mercado de trabalho livre no oeste paulista cafeeiro
}

ROǴÉRIO DA PALMA*

OSWALDO MÁRIO SERRA TRUZZI"*

\section{Resumo}

O pós-abolição vem sendo caracterizado, no que se refere às experiências de ex-escravos e antigos senhores, como um período de redefinição de hierarquias sociais. Um dos assuntos mais instigantes dentro dessa temática é, sem dúvida, a questão dos múltiplos significados atribuídos à liberdade, bem como as diversas maneiras com que ela se associava a outros aspectos da realidade social. Tomando como foco o oeste paulista cafeeiro do início do século XX, o presente artigo pretende demonstrar que, dentro das dinâmicas de sociabilidade constituídas por fazendeiros/administradores e trabalhadores negros, estavam subjacentes disputas acerca de certas formas de articulação entre trabalho e intimidade, enfatizando que essa articulação era uma das chaves para se pensar a liberdade dos egressos da escravidão. Através do exame de um inquérito policial da época, percebeu-se que ex-escravos e seus descendentes estavam empenhados em afirmar um estatuto social de livre, o qual, por sua vez, passava pela atribuição de significados a um determinado ideal de intimidade/privacidade. Argumenta-se, por meio da utilização de conceitos da sociologia econômica, que os conflitos em torno dessa dimensão da liberdade adquiriram, na conjuntura abordada, relevância fundamental dentro do processo social de constituição de um mercado de trabalho livre.

Palavras-chave: Pós-abolição. Sociologia econômica. Mercados de trabalho. Intimidade.

\footnotetext{
* Doutorando em Sociologia na Universidade Federal de São Carlos (UFSCar) e bolsista na Fundação de Amparo à Pesquisa do Estado de São Paulo (FAPESP) - (Brasil). E-mail: rog.cs@ hotmail.com

** Professor Adjunto da Universidade Federal de São Carlos (UFSCar) (Brasil). E-mail: truzzi@ ufscar.br.
} 


\title{
Linkages between intimacy and labor: the social construction of a free labor market in coffee plantations of western São Paulo
}

\begin{abstract}
The post-abolition has been characterized, with regard to the experiences of former slaves and former masters, as a period of redefinition of social hierarchies. One of the most exciting subjects in this theme is certainly the issue of multiple meanings of freedom, and the various ways in which it was associated with other aspects of social reality. Taking as its focus the coffee producing region in the west of São Paulo in the early twentieth century, this article will argue that, within the dynamics of sociability formed by farmers/managers and black workers, there were underlying disputes about certain kinds of linkages between labor and intimacy, emphasizing that this connection was one of the keys to think about the freedom of those leaving slavery. Through the examination of a police inquiry of that time, it was noted that former slaves and their descendants were engaged in holding firm a free social status, which, in turn, demanded assigning meanings to a certain ideal of intimacy/ privacy. Using concepts from economic sociology, we argue that, in the situation addressed, the conflicts over this dimension of freedom have gained fundamental relevance in the social process of creating a free labor market.
\end{abstract}

Keywords: Post-abolition. Economic Sociology. Labor market. Intimacy.

\section{Introdução}

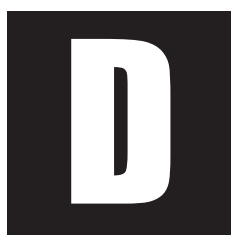

urante os últimos anos, a sociologia econômica tem sido apontada como um dos campos de estudo mais promissores dentro das ciências humanas. O fio condutor das pesquisas realizadas nessa área vem sendo o argumento de que os fenômenos econômicos, vistos muitas vezes como uma esfera absolutamente autônoma, são, na verdade, eminentemente sociais. As ações econômicas não acompanhariam, de maneira cega e uniforme, os caminhos concisos e diretos da racionalização, esta mesma uma construção social por excelência. O próprio mercado - no- 
ção que orienta, em boa parte dos casos, a ideia de "campo econômico" - não deve, na ótica de diversos estudos, ser encarado somente como um mecanismo de formação de preços, passível de ser apreendido pela aplicação de atributos universais e objetivos. Ele seria uma construção histórica em que a subjetividade e a experiência individual dos agentes em interação são de relevância fundamental para a sua compreensão. A sociologia econômica tenta demonstrar, nesse sentido, que a "mão" do mercado é bem visível e materializa-se nas instituições culturais e jurídicas sob as quais as trocas mercantis se assentam. Não existiria, portanto, uma racionalidade econômica absoluta e abstrata, mas sim "limitada pelo contexto", isto é, influenciada por crenças partilhadas e por normas que surgem das relações sociais como um todo ${ }^{1}$.

Um dos exemplos mais cabais dessa, se assim podemos dizer, "concepção social dos mercados" pode ser encontrado em trabalhos que visam avaliar as intersecções entre vida íntima e transações econômicas. Viviana Zelizer (2005a, 2005b, 2009), uma das principais autoras dentro do campo da sociologia econômica, tentou desmontar a ideia de que as atividades econômicas e as relações íntimas formariam "campos hostis". De acordo com ela, muitos encaram essas duas realidades como domínios completamente distintos, os quais, além de operarem segundo princípios diferentes, corrompem um ao outro quando entram em contato direto $^{2}$. Na percepção de Zelizer, o que ocorre é exatamente o contrário: as pessoas estão o tempo todo (re)negociando a combinação entre valores

1 Para uma revisão da literatura e das principais ideias da sociologia econômica, ver Swedberg (2004) Abramovay (2004) e Steiner (2006).

2 Segundo esse princípio, as atividades econômicas estariam norteadas pela lógica da racionalidade, da eficiência e do planejamento, sendo que a vida íntima seria marcada pelo predomínio da solidariedade, do sentimento e do impulso. As crenças de tipo "mundos hostis" afirmam que, quando essas esferas separadas entram em contato, elas se contaminam. Tal mescla corrompe ambas: a invasão do mundo sentimental pela racionalidade instrumental acaba por diminuir o primeiro, enquanto que a intromissão do sentimento em transações racionais produz ineficiência, clientelismo etc. 
pessoais e o universo econômico; as intersecções entre intimidade e relações econômicas acontecem constantemente. Levando-se em conta esse argumento, mas, no entanto, historicizando a própria ideia de intimidade, o artigo pretende esboçar, focando-se na conjuntura do oeste paulista cafeeiro do começo do século XX, uma análise acerca das disputas em torno das intersecções entre trabalho e intimidade presentes nos conflitos entre fazendeiros/administradores e trabalhadores negros. Através do exame de um inquérito policial compilado no município de São Carlos, busca-se demonstrar como que o processo de afirmação da condição de livre, pautado pela recusa em se colocar diante de situações que lembrassem a escravidão, pode ter sido fundamental para o desenvolvimento de um ideal de intimidade entre ex-escravos e seus descendentes diretos. Esse ideal orientava-se pela demanda em poder regular, sem a interferência dos empregadores, as próprias relações familiares. Resguardando cada vez mais as interações familiares das tensões trazidas pelos contatos com administradores e fazendeiros, muitos negros tentavam restringir as hierarquias familiares ao âmbito estritamente doméstico, o que, de certa forma, acabou por afastá-los do regime de trabalho instituído nas grandes lavouras de café. Argumenta-se que essas disputas foram decisivas, portanto, para a configuração social do mercado de trabalho livre que se instala nessa região durante o final do século XIX.

\section{O projeto moralizante da Primeira República e seus ecos no oeste paulista}

No Brasil, a constituição de um regime republicano em fins do século XIX não representou mudanças apenas no que diz respeito às instituições políticas. Aqueles que estavam empenhados em colocar um fim nas estruturas do Império procuravam, na verdade, implantar um novo conceito de Nação no contexto brasileiro. Ancoradas em ideais como os 
de civilização, progresso, raça e higiene, as políticas públicas esmiuçadas durante a "Primeira República" carregavam consigo a ambição modernizante dos seus idealizadores. Ambição orientada, na grande maioria dos casos, pelas novas diretrizes técnico-científicas emanadas da Europa. Mais do que acabar de vez com as instituições políticas imperiais, o objetivo era criar uma nova sociedade, cujos referenciais civilizatórios eram os países europeus tidos como mais avançados.

Historiadores parecem concordar com o fato de alguns ideais terem norteado a constituição dos projetos formulados pelo Estado Republicano que se consolida depois de 1889. Um desses ideais é o que reflete o desejo de a família nuclear burguesa ser o modelo familiar da maioria da população. Buscando compatibilizar os princípios da democracia liberal com os objetivos disciplinadores e eugênicos da república, procurava-se modernizar o país reforçando algumas das tradições católicas consideradas fundamentais para a "evolução humana". Para as autoridades públicas do período, a família era vista como base da nação e como o espaço social produtor de uma mão de obra dedicada, honesta e disciplinada. Caberia ao Estado punir os atos tidos como libidinosos e desenvolver uma moralidade condizente com os padrões civilizados. Tais padrões, por seu turno, seriam aqueles conectados com a concepção conjugal de família. A noção conjugal/individualista de família é uma invenção da modernidade. Segundo Phillippe Ariès (1981), anteriormente ao que se convencionou chamar de época moderna, as sociabilidades familiares mal se distinguiam dos laços de vizinhança, comunitários e "públicos". A sociabilidade conjugal e individualista remete à ideia burguesa de família, a qual se vincula, por sua vez, à produção dos sentimentos de intimidade e de privacidade 3 . Para Michel Foucault (2002), a constituição da família

3 Uma das principais críticas que se pode fazer ao trabalho de Zelizer reside na sua concepção ahistórica de intimidade. Ao ler os seus trabalhos sobre o tema, tem-se a impressão de que a noção de intimidade é um atributo universal, que existiu em todas as épocas e em todos os lugares. 
nuclear se liga, mais precisamente, ao processo de sexualização do corpo da criança. A necessidade de uma maior vigilância direta dos pais sobre os corpos dos filhos, como se pode perceber no caso das campanhas antimasturbação iniciadas no século XVIII, fez com que as relações familiares se enclausurassem na relação direta entre os primeiros e estes últimos.

A família aristocrática e burguesa (já que a campanha se limita precisamente a essas formas de família) até meados do século XVIII, era afinal essencialmente uma espécie de conjunto relacional, feixe de relações de ascendência, descendência, co-lateralidade, parentesco, primogenitura, aliança, que correspondiam a esquema de transmissão de parentesco, de divisão e repartição dos bens e dos estatutos sociais. Era essencialmente as relações que se referiam efetivamente os interditos sexuais. O que está se constituindo é uma espécie de núcleo restrito, duro, substancial, maciço, corporal, afetivo da família: a família-célula no lugar da família relacional, a família-célula com seu espaço corporal, com espaço afetivo, seu espaço sexual que é inteiramente saturado pelas relações diretas pais-filhos (Foucalt, 2002, p. 314).

Concomitantemente, a família nuclear também encerra em si a noção de privacidade, pois a sexualização da infância exige "uma nova física do espaço familiar" (Foucault, 2002, p. 311). Os conteúdos do sentimento de privacidade/intimidade, os quais implicam no acobertamento de certas práticas, florescem na medida em que a casa passar a ser o espaço privilegiado das relações familiares, com uma especialização dos seus espaços internos ${ }^{4}$.

4 A casa como espaço exclusivo das relações familiares é um fenômeno relativamente recente e longe de ser universal. No Brasil colonial, por exemplo, o "morar" e o "produzir" eram inseparáveis. Oficinas, oratórios, casas de beneficiamento de açúcar e até mesmo habitações de escravos formavam a arquitetura de muitas casas senhoriais (Vainfas, 1997, p. 227). A divisão e especialização dos espaços das casas, por sua vez, também seguem o desenvolvimento da noção moderna de privacidade. "A casa ainda hoje é um refúgio, e o quarto um santuário onde se pode extravasar quase tudo, do sono ao sexo, excetuando-se as necessidades para as quais a modernidade contemporânea criou, desde o século XIX, compartimentos específicos no interior da casa. Casa, quarto e cama, eis o tripé, no nível do espaço, da noção contemporânea da privacidade relacionada à sexualidade." (Vainfas, 1997, p. 253). 
No caso da Primeira República brasileira, o próprio Estado encarregou-se de tentar impor de cima para baixo as noções de privacidade. Até então, pode-se dizer que predominava para grande parcela da população uma relação muito fluida entre o público e o privado. Dentro das sociabilidades construídas durante a Colônia e o Império, os ideais de privacidade e intimidade não se apresentavam como conceitos bem delimitados (Vainfas, 1997). Informados pelas teorias higienistas da época, os agentes públicos logo passaram a tentar fixar uma moralidade que fosse conciliável com a nova ordem social. O trabalho transformou-se no principal elemento a ser valorizado, sendo um dos preceitos essenciais na atribuição de um estatuto moral elevado. Junto a ele, por seu turno, foi associada uma série de valores familiares.

A construção de uma ideologia positiva do trabalho veio acompanhada, além de um comportamento laborioso propriamente dito, da difusão de regras higiênicas para os habitantes da cidade e de 'bons' costumes morais. Famílias organizadas, dentro dos padrões médicos, seriam fundamentais para formação do trabalhador, pois incentivariam valores como a assiduidade e responsabilidade. O trabalhador ideal seria aquele que já saísse de casa com os hábitos da rotina doméstica, com as responsabilidades do lar e sem vícios sexuais, pelo menos para evitar o nascimento de crianças ilegítimas. Um trabalhador livre das obrigações domésticas não se adaptaria facilmente à disciplina do trabalho (Esteves, 1989, p. 26-27).

A moralidade, sobretudo nos aspectos relacionados à associação entre trabalho e família, era, nesse sentido, vista como fundamental para a construção adequada de um mercado de trabalho livre no país. Diversos agentes ligados ao poder público, desde juristas e juízes, passando por policiais e delegados, até médicos e agentes sanitários, buscavam estabelecer determinados atributos morais por meio dos projetos que executavam. Tratava-se da tentativa de forjar a modernização brasileira via um projeto moralizante, cuja atuação do Estado adquiria uma posição 
privilegiada. Tal ponto de vista justificaria a necessidade de políticas de cunho moralista frente alguns setores da população. Escrevendo acerca da construção de vilas operárias na cidade de São Paulo durante o início do século XX, Margareth Rago faz o seguinte o relato.

Ao prometer a construção das vilas operárias como respostas para o problema da saúde da população pobre da cidade, os higienistas abrem caminho para a realização da utopia burguesa de fabricação da classe trabalhadora desejada, combinando imperativos econômicos e políticos. Na verdade, muito mais que uma maneira de morar, as vilas representam a vontade de impor sutilmente um estilo de vida [...] É de fundamental importância atingir como alvo privilegiado e seguro esta construção imaginária da sociedade moderna: a família nuclear. A casa deve constituir um novo espaço normalizado de relações estáveis, naturalizadas e assépticas, onde podem se aprofundar os sentimentos familiares e estreitarem-se os vínculos entre os membros da família (Rago, 1985, p. 42).

O ensejo na produção dos sentimentos de intimidade/privacidade estava, portanto, implícito em boa parte das políticas públicas esmiuçadas durante a Primeira República; esses sentimentos seriam fundamentais na construção do perfil ideal de um trabalhador moderno ${ }^{5}$.

5 Esse projeto civilizatório não foi, todavia, aceito passivelmente pela população. Um dos conflitos mais emblemáticos envolvendo essa questão talvez tenha sido o episódio que ficou conhecido como "Revolta da Vacina", ocorrido no Rio de Janeiro em 1904. Essa foi a denominação dada aos levantes populares contrários à instituição da obrigatoriedade da vacina contra varíola, medida que tornou legal a invasão de casas pelos agentes sanitários. As habitações populares cariocas foram, inclusive, foco de outras políticas autoritárias, tais como a reforma urbana promovida pelo prefeito Pereira Passos, que demoliu diversos cortiços do centro da cidade. As habitações coletivas, totalmente desajustadas aos padrões de privacidade que se defendiam, eram vistas como os principais focos de insalubridade e da "perdição" sexual pelas autoridades públicas. Para se interar um pouco mais acerca das tensões e descompassos envolvendo populares e autoridades públicas das grandes cidades, consultar, dentre as obras já citadas, Chalhoub (1996, 2001). Sobre a forma como juristas, delegados e advogados procuravam impor determinados padrões familiares-morais, consultar Caulfield (2000) e Esteves (1985). 
No caso específico do "novo" oeste paulista6 , o próprio regime de trabalho instituído nas fazendas de café após o fim do escravismo trazia consigo a necessidade de certos pressupostos familiares. O colonato, como ficou conhecido, era um regime de trabalho que possuía a família como unidade produtiva básica, ou seja, eram os laços familiares o parâmetro para a delimitação dos trabalhos e dos pagamentos. No começo do ano agrícola, ficava demarcado, de acordo com o número de pessoas aptas ao trabalho de cada família, o percentual de pés de café que essa ficaria responsável por cuidar. Ao final da colheita, o pagamento por esse trabalho era também realizado levando-se em conta a quantidade de frutos colhidos por toda a unidade familiar ${ }^{7}$. Alguns estudos, por sua vez, afirmam que esse caráter estritamente familiar vigente no colonato não pode ser tributado a uma racionalidade puramente econômica dos fazendeiros da região, empenhados simplesmente em maximizar seus ganhos. Segundo Verena Stolcke (1982), o colonato não foi instituído meramente por "forças ligadas ao mercado", mas também devido a um "familismo" presente entre fazendeiros e trabaIhadores, os quais enxergavam a necessidade de apresentar a família como um grupo coeso em torno da cooperação no trabalho ${ }^{8}$. O colonato, desse

6 O "Oeste histórico" inclui o "Oeste velho" (o "quadrilátero de açúcar", centrado na região de Itu a Campinas), o qual se expande como área de "grande lavoura" (produzindo açúcar e, mais tarde, café) a partir de 1790, e o "Oeste novo" (de Rio Claro para o norte-noroeste), que se consolida como área cafeeira principalmente após 1850 (Slenes, 1997, p. 456). São Carlos, município onde se desenrolam os conflitos que serão analisados, faz parte do chamado "oeste novo".

7 O colonato estava estruturado a partir de uma determinada lógica familiar, a qual trazia consigo designações acerca da conceitualização do binômio masculino/feminino e dos papéis familiares, bem como das relações destes com o universo do trabalho. O marido e os filhos mais velhos encarregavam-se do trabalho constante nos cafezais, enquanto que mulheres e filhas maiores faziam o serviço doméstico, cuidavam da lavoura da subsistência e auxiliavam nos cafezais durante a colheita e em momentos de maior trabalho.

8 Esse tipo de abordagem possui o mérito de não conceber o processo histórico de abolição do trabalho escravo, e a consequente implantação de um novo regime de trabalho, como uma simples "transição" do mundo da escravidão para o universo do trabalho livre. Ao buscar compreender a instauração do colonato a partir dos conflitos concretos envoltos nas relações entre 
ponto de vista, foi gestado dentro de disputas que transpassavam a mera questão da eficiência do regime de trabalho; elas estavam, também, imersas em conflitos pela definição de uma determinada gramática moral, a qual associava certas relações familiares com o trabalho.

Como visto, muitos estudos discorreram acerca das tensões envoltas nas tentativas de agentes estatais da Primeira República quanto à imposição de uma dada moralidade, principalmente quando nos referimos às principais cidades do país. Porém, como será que se processaram as disputas em torno das lógicas morais dentro da conjuntura das fazendas de café do oeste paulista? Há que se considerar que foi essa região o destino da maioria dos imigrantes subsidiados pela política imigratória formulada pelo governo paulista. A partir de 1884, momento em que o fim do regime servil aparecia como algo iminente, o governo da então província de São Paulo resolveu elaborar uma política de subsídio à vinda de trabalhadores imigrantes, passando a financiar integralmente a vinda de europeus que se disponibilizassem a trabalhar nas fazendas do interior. Estima-se que cerca de dois milhões de estrangeiros vieram para São Paulo até 1927, data em que se encerra a política de subsídio, sendo que grande parte desse contingente teve como destino os cafezais do interior (Andrews, 2007, p. 171). Esses novos trabalhadores passaram a predominar numericamente na ocupação de colono das fazendas, encarregando-se dos trabalhos antes efetuados por uma quantidade expressiva de escravos. Há autores (Hofbauer, 2003; Schwarcz, 1995; SEYFERTH, 1996) que enxergam um racismo intrínseco na política imigratória em

patrões e empregados, Stolcke escapa das análises que acabam por cristalizar as concepções de trabalho escravo e trabalho livre. Distintas noções de liberdade e trabalho livre estiveram em luta durante a virada do século XIX para o XX; durante toda a escravidão, também foram produzidas pelos escravos diversas percepções acerca do que é liberdade. Não se deve associar, direta e mecanicamente, liberdade ao trabalho livre e opor, direta e mecanicamente, liberdade e escravidão. Uma crítica acerca da suposta historicidade presente na "teoria da transição" está em Lara (1998). 
questão. Segundo esta corrente, os embates acerca da construção de uma nacionalidade estavam, em fins do século XIX, vinculados diretamente à questão racial. Influenciada pelo pensamento racial europeu, boa parcela daqueles que pensavam o futuro do país entendia o suposto "atraso" brasileiro como fruto da grande presença de afro-descendentes em sua cultura. Tendo em mente o avanço da "civilização" no território brasileiro, seria necessário, portanto, um "embranquecimento" da população que o compunha. A vinda de trabalhadores europeus, nesse sentido, casava-se com o desejo de membros das classes dirigentes em promover uma "desafricanização" do Brasil. Tudo o que representava o "progresso" - a abolição da escravidão, o trabalho livre, a derrubada do regime monárquico etc. - quase sempre se ligava a perspectivas propriamente raciais sobre o desenvolvimento do país.

Chama a atenção o fato de que todos os projetos políticos que visavam abolir a escravidão vinculavam a implementação da 'abolição' à idéia da importação de mão-de-obra européia (= 'branca'). Baseados numa concepção já mais 'naturalizada' de 'negro' e 'branco', os 'espíritos progressistas' da época estavam convencidos de que a 'mão-de-obra branca' seria mais produtiva que a 'mão-de-obra negra'. 'Branco já não simbolizava mais exclusivamente valores morais-religiosos nem só o status de liberdade: agora a cor branca seria também projetada na idéia de progresso (Hofbauer, 2003, p. 79-80).

Alguns autores (Martins, 1973; Azevedo, 2000) argumentam que os fazendeiros do oeste paulista nutriam uma clara preferência pelos trabaIhadores estrangeiros, sobretudo porque, na percepção deles, esses últimos apresentavam os atributos morais propícios ao trabalho livre. Assim como boa parte dos políticos e da burocracia do Estado republicano, os grandes proprietários também faziam questão de atribuir uma conceitualização moral ao novo regime de trabalho. 
Dentro da historiografia sobre o pós-abolição, não são poucos os trabalhos que descrevem a existência de uma visão alternativa da vida econômica entre os egressos da escravidão. Tal visão, interpretada a partir dos conflitos travados durante o desenrolar do processo de abolição e da codificação das teorias raciais do período, foi a base para a ressignificação de uma série de estereótipos. Com o intuito de se afastar do antigo estatuto de cativo, ex-escravos e seus descendentes passaram, de um modo geral, a exigir maior autonomia nas relações de trabalho, bem como requeriam maior controle sobre sua mobilidade e sobre o seu próprio tempo. As expectativas e planos contidos nesse projeto, contudo, logo foram subentendidos pelas elites reformistas como uma prova cabal da não adaptabilidade dos afro-brasileiros ao trabalho livre. O projeto alternativo de muitos dos recém egressos do cativeiro foi, nesse sentido, estigmatizado e transformado no alicerce para os estereótipos do negro preguiçoso e avesso ao trabalho. Não tardou, dessa maneira, para se consolidar uma percepção segundo a qual os ex-escravos seriam inaptos ao trabalho não-coagido ${ }^{9}$. O que resta saber, contudo, é como essa percepção era operacionalizada e contestada dentro das sociabilidades encerradas no universo do trabalho, ou seja, para aqueles negros que permaneceram trabalhando nos cafezais paulistas posteriormente à chegada em grande escala de imigrantes, como se processou as apropriações e as tentativas de desvinculação em relação a esses estereótipos? As relações familiares, bem como toda a gramática moral relacionada a essas interações, tiveram relevância nesses embates? Poderia a problemática envolta nos ideais de privacidade e intimidade, tão cara para os projetos republicanos, tencionar ainda mais estes embates? São estas questões que se pretende abordar

9 Uma síntese de como se processou, em diversos contextos da América Latina, a produção dos preconceitos em relação aos projetos de vida de ex-escravos está em Cooper, Holt e Scott (2005). 
a partir da discussão de um inquérito policial compilado no município de São Carlos. Acredita-se que a análise desse conflito particular pode trazer mais pistas acerca das estratégias traçadas pelos afro-brasileiros durante o pós-abolição e, sendo assim, auxiliar na compreensão do processo de construção social do mercado de trabalho em questão.

\section{As disputas em torno da articulação entre trabalho e intimidade: as tensões nas dinâmicas de sociabilidade das fazendas do oeste paulista}

O regime de colonato não acarretou mudanças apenas na esfera estritamente produtiva, mas também nas relações de poder que atravessavam as interações pessoais de fazendeiros com seus (agora) empregados. Quando o trabalho nas lavouras ainda era tocado pelo braço escravo, muitos senhores prometiam alforrias, gratificações e melhores trabalhos para os escravos mais leais, com o intuito de consolidar a sua posição através do estabelecimento de laços morais com os cativos. No colonato, como o trabalho das mulheres e dos mais jovens estava subordinado ao pai de família, isto é, a distribuição de tarefas e dos rendimentos se efetuava dentro da unidade familiar, os fazendeiros perderam parte desses mecanismos de dominação que antes dispunham (Slenes, 1997, p. 287). Os referencias hierárquicos inscritos nas relações familiares eram, agora, determinantes para a dinâmica de sociabilidade circunscrita ao universo do trabalho.

Muitos fazendeiros, assim como aqueles que exerciam alguma autoridade na supervisão do trabalho das fazendas de café, como era o caso dos administradores, continuaram, entretanto, tentando regular as relações pessoais de seus trabalhadores. Vários deles, aliás, passaram para a intimidação e para a violência física como forma de manutenção da sua autoridade. Em 
São Carlos $^{10}$, por exemplo, no dia 1 de Novembro de 1907, Sebastião Leite, preto, 30 anos, trabalhador de roça, solteiro, foi agredido pelo administrador da fazenda onde morava. O motivo foi a insistência deste último em intervir numa discussão tida pelo primeiro com a sua amásia, Ana Maria de Jesus, parda, 30 anos, doméstica, solteira ${ }^{11}$. Sebastião teria ido a uma venda para beber junto com Ana e mais um amigo do casal; chegando à sua casa, teve uma discussão com aquela e acabou sendo interpelado por Jeremias Oliveira Barbosa, 40 anos, administrador, casado.

No dia primeiro do corrente, ás nove horas da noite, mais ou menos, Sebastião Leite, colono na fasenda da 'Horta', sita neste município, teve dentro da própria casa, forte alteração com a sua amasia Anna Maria de Jesus, por ter querido esta abandonal-o e ir viver em companhia de um tal Alexandre, presente na occasião. [ilegível] no meio dessa contenda, quando alli appareceu o administrador da fasenda - o denunciado Jeremias Barbosa - que, dirigindo-se a Sebastião Leite, armado de um podão, deu-Ihes varias pancadas, occasionando-Ihe os ferimentos descritos no auto de corpo de delito [...] (Fundação Pró-Memória de São Carlos, caixa 199, no 118, 1907).

Jeremias afirmou ter ido três vezes à casa de Sebastião para pedir que parasse com os "distúrbios" que estava promovendo. Disse que na terceira vez, a qual ocorreu quando ele já havia inclusive "tocado silêncio na fazenda", Sebastião avançou para cima dele. Ao tentar se defender e,

10 São Carlos constitui-se como uma típica região cafeeira do "novo" oeste paulista. Iniciou o plantio de grandes quantidades de café por volta da metade do século XIX, ainda com a utilização de escravos. Posteriormente, consolidou sua produção com a chegada de trabalhadores estrangeiros, sendo um dos municípios da região que mais recebeu imigrantes durante a virada do século XIX para o século XX. Para uma consulta à história de São Carlos, ver Truzzi (2000). 11 Serão reproduzidos de forma literal os termos e classificações atribuídos aos indivíduos no inquérito. Essas designações, contudo, são irregulares. Todas as informações transcritas acerca dos envolvidos seguem, portanto, o que se conseguiu apreender nos documentos. 
nas suas próprias palavras, manter a sua "força moral como administrador", acabou por agredir o seu subordinado com um podão que trazia nas mãos. Essas declarações de Jeremias apontam para o fato de que, dentro das fazendas de café, o poder incumbido de normativizar os trabaIhadores se concentrava nas autoridades da fazenda, principalmente nos administradores ${ }^{12}$. Diferentemente dos grandes centros urbanos, onde o Estado encarregava-se de lançar à base da força um projeto moralizador de nação, nos centros da economia cafeeira do oeste paulista, as autoridades da fazenda eram os detentores da função de manter a "ordem moral". Os administradores davam o toque de recolher e, assim, proibiam as manifestações de lazer, bem como qualquer espécie de distúrbio, após esse período. Eram eles que delimitavam as visitas que os trabalhadores poderiam receber e quando eles as receberiam; as autoridades da fazenda também encarregavam-se de intermediar qualquer tipo de conflito entre os empregados da fazenda, mesmo que eles não envolvessem questões diretamente relacionadas ao trabalho.

Para poder impor as normas sociais que orientavam a sociabilidade dentro dos limites das propriedades, os poderes conferidos ao administrador deveriam, de um modo geral, desfrutar de certa validade frente aos trabalhadores. A maioria utilizava-se das intimidações, fosse por meio verbal ou até mesmo da violência física, para manter o seu estatuto. O discurso de Jeremias deixa claro exatamente essa faceta da posição de administrador: a não obediência de Sebastião aos seus mandos, e ainda por cima a suposta tentativa de agredi-lo, poderia minar a sua autoridade com os outros empregados. Jeremias deveria, a qualquer custo, afirmar o seu "lugar" dentro das interações mantidas com seus subordinados. O "lugar" é uma

12 O que aqui designamos de "autoridades da fazenda" são os administradores e seus ajudantes, os diretores de colônia, fiscais e os próprios fazendeiros. Esses são os cargos que gozavam do poder de impor certas práticas disciplinares aos demais trabalhadores. 
dessas expressões que, mesmo quando utilizadas de maneira implícita, traduzem normas de sociabilidade assimétricas, as quais, sendo referendadas ou contestadas, atualizam-se cotidianamente. É construindo e conhecendo tais "lugares" que as pessoas estabelecem relações, reconhecem formas de pertencimento e estruturam disputas próprias ao jogo social (Albuquerque, 2009, p. 33). Segundo o depoimento de Ana Maria, Jeremias, antes de agredir fisicamente o seu amásio, proferiu a seguinte frase: "[...] seu cachorro você não me obedece mesmo". O argumento propalado pelo advogado do réu, segundo o qual o seu cliente teria agido "em legítima defesa", convenceu os juízes e Jeremias Barbosa acabou sendo absolvido.

O empenho de administradores em manter determinada ordem nas fazendas esbarrava, muitas vezes, nos próprios códigos morais dos trabaIhadores. Sebastião Leite, por exemplo, não acatou as ordens de Jeremias muito provavelmente porque se considerava no direito de resolver os seus problemas conjugais sem ser interrompido por terceiros. O assédio de outro homem à sua amásia parecia uma questão séria demais, sendo que os mandos do administrador e o "toque de silêncio" acabaram ficando em segundo plano. Se observarmos mais atentamente o contexto histórico em que esse conflito se desenrola, ou seja, menos de vinte anos após a abolição, perceberemos que, nas suas entrelinhas, estão presentes contornos muito específicos. Terminado o escravismo, muitos fazendeiros e ex-escravos tentaram utilizar-se das mesmas estratégias que adotavam nos tempos de escravidão, mas tentando estabelecer novas formas de distinção social (Albuquerque, 2009, p. 113; Fraga Filho, 2006). A Abolição, mesmo não sendo uma ruptura radical, não representou somente o fim de uma relação de propriedade, mas também a perda das referências fundamentais na constituição da identificação de escravos e senhores. A certeza de que o mundo social não podia ser interpretado a partir do binômio senhor/ escravo comprometia vínculos pessoais e referências de autoridade, e não 
somente relações de trabalho. Não eram apenas os trabalhadores que os proprietários perdiam, mas a sua própria posição hierárquica estava em jogo. Havia todo um "lugar social" construído desde o período colonial em torno dessas duas categorias. Muitos ex-senhores, ao fim da escravidão, viram-se fora desse lugar que estruturava toda a lógica da arquitetura social. Com o fim definitivo do escravismo, portanto, foram suspensas diversas regras que balizavam as disputas de poder entre senhores/brancos e subalternos/negros (Albuquerque, 2009, p. 125-126). O direito de poder regular autonomamente as relações familiares era, por seu turno, um dos parâmetros de demarcação, entre ex-escravos e seus descendentes, da distinção entre o "tempo do cativeiro" e o "tempo da liberdade" (Castro e Rios, 2005, p. 50). A constituição de um ideal de liberdade passava, além da questão mais diretamente relacionada ao trabalho e à mobilidade, pelo estabelecimento de determinadas lógicas familiares, muitas delas dificultadas, ou então até mesmo impedidas, durante a escravidão. Para quem teve conhecimento, seja por experiência própria ou pelas histórias contadas por conhecidos, das separações causadas pelo tráfico interprovincial ${ }^{13}$, tal busca não se apresenta como algo de pouca relevância. Ter os laços familiares rompidos segundo a vontade de senhores foi, para muitos dos escravos que migraram forçadamente para o Sudeste, uma das piores experiências do escravismo (Chalhoub, 1990, p. 27).

Sebastião Leite tinha 30 anos em 1907. Nasceu, portanto, após a Lei do Ventre Livre, promulgada em $1971^{14}$. Não sabemos se ele era des-

13 Posteriormente ao fim do tráfico de escravos da África para o Brasil, em 1850, ocorre um intenso fluxo de cativos do Nordeste para as fazendas de café do Sudeste. Os fazendeiros localizados nessa última região passaram, movidos pelo crescimento da exportação de café, a comprar escravos oriundos das economias que se encontravam em declínio.

14 A Lei do Ventre Livre, também conhecida como "Lei Rio Branco", estabelecia, dentre outras determinações, que todos os filhos de escravos nascidos a partir daquela data seriam considerados livres. Filhos de mães escravas, os ingênuos beneficiados por essa lei eram obrigados a ficar sob a tutela dos senhores de suas mães ou do governo até completarem a maioridade. 
cendente direto de escravos e, com isso, se esteve sob a tutela de algum senhor durante os primeiros anos de vida, pois, pela sua idade, pode-se inferir que, quando nascera, ainda perdurava o escravismo. Somente por ter vivenciado os últimos anos de escravidão, entretanto, Sebastião deve ter presenciado experiências ou ouvido histórias acerca das ações de senhores contra as relações familiares tecidas por cativos. Além do mais, o processo de racialização que emerge na segunda metade do século XIX colocou, aos olhos de muitos, toda a população negra em pé de igualdade, uma vez que os negros livres não mais gozavam desse adjetivo como forma de distinção social. Não apenas aqueles que haviam concretamente experimentado a condição escravo estavam, nesse sentido, empenhados em se livrar dos estereótipos pós-cativeiro. É de se presumir, portanto, que a interferência nas suas desavenças familiares significava, para Sebastião, uma tentativa de colocá-lo na mesma posição que a de um escravo. A reafirmação do seu estatuto social de livre passava, desse modo, pela consolidação da identificação com certos papéis familiares; nesse caso específico, com o papel de marido. Quando esta identificação era colocada em xeque, como na situação descrita no inquérito, as possibilidades de conflitos poderiam aumentar consideravelmente ${ }^{15}$.

\footnotetext{
Na prática, muitos escravocratas mantiveram os ingênuos nas suas propriedades, tratando-os como se fossem escravos.

15 Analisando diversos inquéritos policiais compilados em São Carlos, inclusive este inquérito que agora abordamos, Karl Monsma (2005a) percebeu que a reivindicação de respeito pela privacidade era comum entre os negros quando se observa os conflitos destes com fazendeiros da região. Na visão desse autor, essa seria uma forma dos afro-brasileiros exigirem igualdade de tratamento e, por conseguinte, distanciamento da condição de escravo. Também segundo ele, os fazendeiros, extremamente sensíveis a qualquer tentativa de deslocamento dos referenciais hierárquicos, interpretavam esses comportamentos como desacato e logo partiam para a agressão física contra seus subordinados.
} 
Diante disso, é possível supor que havia um ideal de intimidade/ privacidade sendo forjado, por parte dos ex-escravos e seus descentes, nas disputas em torno da afirmação do seu estatuto de livres. Esse ideal, como era de se esperar, não seguia os padrões higienistas propostos pelas principais políticas públicas da época. Era uma privacidade construída a partir das limitações que a sua própria condição impunha. Não se visava estabelecer laços apenas dentro da lógica da família nuclear, nem mesmo abolir de vez o morar conjunto entre famílias (Wissenbach, 1998). Os sentidos da privacidade eram direcionados, sobretudo, à possibilidade de regulação autônoma dos referenciais hierárquicos presentes na gramática familiar, primordialmente quando se tratava das interações mantidas com aqueles que os empregavam. A interferência nas relações familiares, por parte de fazendeiros ou então de administradores, trazia, muito provavelmente, reminiscências do escravismo. A renegociação do seu estatuto social fez com que diversos afro-brasileiros se empenhassem em distinguir, da melhor maneira possível, as relações familiares das outras formas de sociabilidade; esse, por sua vez, era um dos princípios construtores da sua dimensão de intimidade. A privacidade da família, se assim podemos chamar, aparece como algo que deveria ser respeitado, principalmente por aqueles que ainda se enxergavam como "senhores" - ou mesmo como feitores, caso de muitos administradores.

Sob este ângulo, parece legítimo supor que estas disputas em torno das dimensões da privacidade dos trabalhadores negros foram significativas na constituição do mercado de trabalho do oeste paulista pós-abolição. Analisando a competição entre negros e imigrantes dentro da economia cafeeira, Andrews (2007, p. 170) constrói argumentos interessantes para explicar a falta de competitividade dos primeiros. Para ele, os exescravos, agora como livres, não mais aceitavam se sujeitar a condições de trabalho encaradas como depreciativas. Uma dessas condições tidas 
como depreciativas era o emprego de mulheres e crianças no trabalho lavoura. Devido a isso, havia uma relativa resistência dos afro-brasileiros ao trabalho no regime de colonato.

Tanto os fazendeiros como os ex-escravos viam o trabaIho feminino e infantil como um componente integrante da instituição recentemente abolida da escravidão. Os fazendeiros estavam determinados a manter esta prática, e os ex-escravos estavam determinados a pôr um fim nisso. Os fazendeiros prevaleceram, principalmente importando trabalhadores imigrantes que, não tendo uma história de escravidão nas fazendas aceitavam incluir as mulheres e as crianças no contrato de colonato. Famílias de italianos, de espanhóis e de outros europeus substituíram os afro-brasileiros nas grandes propriedades, com consequências devastadoras para a mobilidade ascendente a longo prazo do afro-descendentes em São Paulo (Andrews, 2007, p. 170).

Tal expectativa quanto ao trabalho dos familiares demonstra que, realmente, diversos ex-escravos não estavam suscetíveis a permitir que seus filhos e mulheres recebessem ordens de outras pessoas ${ }^{16}$. Isso fez com que muitos deles não vissem com bons olhos a possibilidade de morar e trabalhar nas fazendas. As potenciais ingerências nas relações familiares, como aconteceu no atrito entre Sebastião e Jeremias, não eram aceitas por boa parte dos afro-brasileiros que já conheciam o contexto da economia cafeeira. Nesse sentido, relata Andrews, a força política dos fazendeiros, tornando possível uma política de atração dos trabalhadores desejáveis e, dessa maneira, evitando a necessidade de intensas negociações com libertos, teria sido essencial para que os estereótipos raciais, agora ressignificados, funcionassem plenamente como marcadores sociais que hierarquizavam o mercado de trabalho.

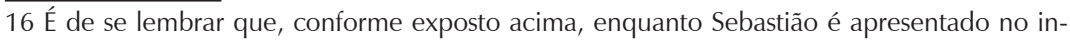
quérito como "trabalhador de roça", Ana Maria é designada "doméstica". 
Os conflitos entre fazendeiros e administradores, por um lado, e afro-brasileiros, por outro, perpassavam também, dessa maneira, pelo estabelecimento dos sentidos e significados a serem atribuídos à privacidade desses últimos. Diferentemente de vários ex-senhores, que ainda seguiam, nas interações com seus trabalhadores, os antigos referenciais de autoridade, muitos negros procuravam preservar mulheres e crianças dos tensos contatos com os patrões, gestando, a partir da restrição das relações familiares ao espaço puramente doméstico, um certo ideal de intimidade. Essa restrição trazia uma especificidade cada vez maior para as sociabilidades familiares, afastando-as cada vez mais das relações de trabalho. Afastandoas cada vez mais, é bom deixar claro, das novas relações de trabalho, as quais possuíam como parâmetro os referenciais inscritos na relação patrãoempregado. As mulheres estariam, assim como Ana Maria, incumbidas dos afazeres circunscritos ao espaço da casa ${ }^{17}$. Em parte devido a isso, não são poucos os negros que preferem mudar para as cidades após a conquista da liberdade. Nem sempre foi possível sustentar a família apenas com o trabalho do marido ou de um único filho. Nas áreas urbanas, as mulheres poderiam realizar trabalhos como lavadeiras ou então como vendedoras de alguns produtos, adicionando dinheiro para a economia doméstica sem terem que enfrentar diretamente a relação patrão-empregado.

Todos esses fatores tiveram sérias consequências na competição pelos postos de trabalho dentro do regime de colonato. Os imigrantes, além de usufruírem de uma melhor imagem perante os grandes proprietários

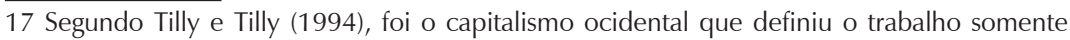
como aquelas atividades remuneradas. Com um olhar mais amplo, é possível perceber diversos "mundos do trabalho", variando de acordo com os sentidos e significados atribuídos a ele em cada contexto. 
rurais, não faziam restrição quanto ao emprego de filhos(as) e esposas no trabalho da lavoura ${ }^{18}$. Se pelo lado dos afro-brasileiros as tensões envolvendo o forjamento de uma intimidade familiar eram um campo de disputa acerca da renegociação de estatutos sociais, elas não deixaram de ser apropriadas de outra forma por terceiros. $\mathrm{O}$ processo de racialização das relações de trabalho conduzido no oeste paulista se alimentou desses conflitos para criar e reforçar uma série de estereótipos em relação à população negra. Suas reivindicações quanto à privacidade das relações familiares foram muitas vezes interpretadas, assim como no episódio analisado, enquanto "distúrbios" e, tratando-se de outras situações, como indisposição para o trabalho propriamente ${ }^{19}$. As desavenças, nesse caso, serviam, para fazendeiros e seus administradores, como mais uma justificativa da não adaptabilidade dos negros à nova ordem de trabalho.

18 Juntamente com a subordinação aos poderes da sogra, o trabalho fora de casa era um dos aspectos com os quais as italianas mais se sentiam incomodadas em relação ao casamento com cônjuges da mesma nacionalidade (Monsma, Truzzi, Bôas, 2005b, p. 190-191).

19 Convém explicitar que essa disposição, apresentada pelos trabalhadores negros, para uma regulação autônoma das relações familiares trazia profundas consequências para as hierarquias constituídas em torno dos binômios marido/mulher e pai/filhos(as). Em seu depoimento, por exemplo, Ana Maria relata ter levado dois tapas de Sebastião, mesmo após ter negado o convite de Alexandre "para ir para a sua companhia". É de se sugerir que pais/maridos afrobrasileiros, na tentativa de mostrar autoridade, acabavam buscando aumentar o seu poder de controle sobre mulheres e filhos(as). Devido a esse enrijecimento dos pressupostos hierárquicos presentes na gramática familiar, pode-se inferir que não foram raras as vezes em que as laços familiares tecidos por negros(as) desembocaram em conflitos que chegaram até mesmo a agressão física. Esse pelo menos foi o caso da relação de Sebastião e Ana Maria. Os significados da intimidade, e muito possivelmente as suas associações com os sentidos atribuídos ao trabalho, formavam um campo de disputas também dentro das próprias relações familiares, haja vista que mulheres e filhos(as) poderiam contestar a rigidez dos referenciais de autoridade. 


\section{Considerações finais}

A intimidade e as relações familiares nela encerradas eram valores centrais dentro do projeto republicano de Nação. Mais do que uma reforma puramente econômica, a desagregação do escravismo deveria ser também uma reforma moral. No caso do oeste paulista cafeeiro, a adoção do colonato parece estar intrinsecamente ligada aos empenhos, expressos durante o processo abolicionista, em se arquitetar maneiras de se moralizar as relações de trabalho. Calcado no trabalho familiar, este regime colocava como pressuposto uma dada lógica familiar, a qual, na percepção sobretudo de fazendeiros, deveria estar presente nas normas de sociabilidade pós-escravistas. À sombra da Abolição e da constituição da República, contudo, estavam também sendo construídos, a partir de intensas disputas, os sentidos sociais e políticos da liberdade e da cidadania para a chamada "população de cor". Era consenso entre todos os agentes envolvidos, mas principalmente para os ex-escravos, que o pós-abolição era um momento decisivo na redefinição das relações sociais. Os egressos da escravidão, de um modo geral, tiveram que se afirmar enquanto livres e, mais do que isso, criaram seus próprios entendimentos acerca do que era ser livre. Ao longo de todas as suas experiências, escravos e libertos construíram uma série de concepções de liberdade. Essas concepções variavam de acordo com a conjuntura, mas quase sempre passaram pela disputa em torno da atribuição de sentidos a conceitos como trabalho, raça, cidadania, mobilidade etc. A liberdade, desse modo, não pode ser encarada como um valor absoluto e totalmente dissociado da escravidão, mas sim um ideal construído a partir das diversas apropriações realizadas sobre a sua própria definição.

Como vimos ao longo do artigo, muitos negros esboçaram, a partir das experiências e associações em relação à condição de cativo, um projeto de vida econômica - estruturado segundo o que conceitualizavam como liber- 
dade - o qual batia de frente com os anseios modernizantes hegemônicos. Mais precisamente, observando o conflito abordado, pôde-se perceber que um ideal específico de intimidade era um dos códigos morais presentes na afirmação do estatuto social de homem livre. Distinto dos padrões de intimidade esboçado pelas elites reformistas e concretizado a partir dos limites impostos pelas próprias condições, esse ideal buscava isolar as relações familiares, principalmente tratando-se de determinados referenciais hierárquicos. Pais e maridos de ascendência escrava procuravam, agora como livres, não mais permitir que terceiros interferissem diretamente na sua gramática familiar. Levando-se em conta a conjuntura das fazendas de café do oeste paulista, argumentou-se que os sentidos atribuídos a essa noção de privacidade exerceram influência significativa na trajetória de ex-escravos e seus descentes. Uma vez que as interações sociais tecidas dentro do regime de colonato não autorizavam a prática dessa intimidade, muitos deles não viam com bons olhos esse regime de trabalho. O confronto envolvendo Sebastião e Jeremais demonstrou que qualquer tipo de conflito ocorrido dentro do espaço das fazendas cafeeiras estava suscetível às hierarquias constituídas nas relações de trabalho.

As tensões exprimidas no embate tratado são, por sua vez, úteis para se pensar o processo histórico de construção social de um mercado de trabalho abordado. Para além da questão da eficiência do trabalho livre em relação ao trabalho escravo, a conformação específica do colonato, um dos diversos "regimes de trabalho livre" que se instauram no país posteriormente ao fim do escravismo, foi muito influenciada pelas lutas político-sociais envolvendo alguns agentes. Como bem disse Wlamyra Albuquerque (2009, p. 112), as relações de trabalho pós-abolição refletiram as diversas concepções de raça, política e cidadania que cada conjuntura produziu; as estruturas de trabalho dialogavam com experiências herdadas do escravismo e com as concepções acerca do trabalho 
livre. Nesse artigo, procurou-se explicitar como que uma forma específica de articulação entre intimidade e trabalho afastou parcela da população negra da competição por trabalho nas fazendas do oeste paulista. A operacionalização dessa articulação foi, por seu turno, interpretada a partir de determinados filtros e apropriada por discursos que transformaram visões acerca do que é ser livre em estereótipos negativos ${ }^{20}$. A política imigratória do governo de São Paulo garantiu, desse modo, um poder de barganha maior aos fazendeiros interessados em ressignificar os padrões de exclusão sob os quais o escravismo estava fundado. O processo de racialização das relações sociais que acompanha a Abolição foi, nesse sentido, decisivo para a configuração de um mercado de trabalho livre no oeste paulista cafeeiro, demonstrando que as disputas envoltas nos significados do trabalho ultrapassavam a mera questão do acionamento de uma racionalidade puramente econômica.

\section{Fontes primárias}

Inquéritos Policiais. Fundação Pró-Memória, São Carlos.

\section{Referências}

ABRAMOWAY, Ricardo. Entre Deus e o Diabo: mercado e interação humana nas Ciências Sociais. Tempo Social, São Paulo, v. 16, no 2, p. 35-64, nov. 2004.

ALBUQUERQUE, Wlamyra. O jogo da dissimulação. Abolição e cidadania negra no Brasil. São Paulo: Companhia das Letras, 2009.

ANDREWS, George Reid. Negros e Brancos em São Paulo. Bauru: Edusc, 1998.

20 Por serem, muitas vezes, operacionalizadas na classificação de determinados grupos sociais, a intimidade e as relações afetivas estão adquirindo cada vez mais destaque dentro das análises que tratam dos contínuos processos de (re)construção de determinadas categorias étnico-raciais. Ver o caso da relevância dessa temática para os estudos das migrações italianas firmadas ao redor do mundo em Baldassar e Gabaccia (2010). 
ANDREWS, George Reid. América Afro-latina, 1800-2000. São Carlos: Edufscar, 2007.

ARIÈS, Philippe. História Social da criança e da família. Rio de Janeiro: Guanabara Koogan, 1981.

AZEVEDO, Célia Maria Marinho. Onda negra, medo branco: o negro no imaginário das elites, século XIX. São Paulo: Annablume, 2004.

BALDASSAR, Loretta; GABACCIA, Donna. Home, Family, and the Italian Nation in a Mobile World. The Domestic and the National among Italy's Migrants. In: Intimaçy and Italian Migration. Gender and Domestics Lives in a Móbile World. New York: Fordham University Press, 2010, p. 1-22.

CAULFIELD, Sueann. Em defesa da honra. Moralidade, modernidade e nação no Rio de Janeiro (1918-1940). Campinas: Editora da Unicamp, 2000.

CASTRO, Hebe Mattos; RIOS, Ana Maria. Memórias do Cativeiro: Família, trabalho e cidadania no pós-abolição. Rio de Janeiro: Civilização Brasileira, 2005.

CASTRO, Hebe Mattos; RIOS, Ana Maria. Laços de Família e Direitos no Final da Escravidão. In: ALANCASTRO, Luiz Felipe (Org.). História da Vida Privada no Brasil 2. Império: a Corte e a Modernidade. São Paulo: Cia das Letras, 1997, p. 337-384.

CHALHOUB, Sidney. Trabalho, lar e botequim. O cotidiano dos trabalhadores no Rio de Janeiro da Belle Époque. Campinas: Editora da Unicamp, 2001.

CHALHOUB, Sidney. Cidade febril. Cortiços e epidemias na Corte Imperial. São Paulo, Companhia das Letras, 1996.

CHALHOUB, Sidney. Visões da liberdade. Uma história das últimas décadas da escravidão da corte. São Paulo: Companhia das Letras, 1990.

COOPER, Frederick; HOLT, Thomas; SCOTT, Rebecca. Além da escravidão: investigação sobre raça, trabalho, e cidadania. Rio de Janeiro: Civilização Brasileira, 2005.

ESTEVES, Martha de Abreu. Meninas perdidas. Os populares e o cotidiano do amor no Rio de Janeiro da Belle Époque. Rio de Janeiro: Paz e Terra, 1989.

FOUCAULT, Michel. Os anormais. Curso no Collège de France (1974-1975). São Paulo: Martins Fontes, 2002.

FRAGA FILHO, Walter. Encruzilhadas da liberdade. História de escravos e libertos na Bahia (1870-1910). Editora da Unicamp: Campinas, 2006.

HOFBAUER, Andreas. O conceito de 'raça' e o ideário do 'branqueamento' no século XIX - Bases ideológicas do racismo brasileiro. Teoria \& Pesquisa, São Carlos, vol. 1, n. 42, p. 63-110, jan./jul. 2003. 
HOLLOWAY, Thomas. Imigrantes para o café: café e sociedade em São Paulo, 1886-1934. Rio de Janeiro: Paz e Terra, 1984.

LARA, Silvia Hunold. Escravidão, Cidadania e História do trabalho no Brasil. Projeto História, São Paulo, n. 16, p. 25-38, fev. 1998.

MARTINS, José de Souza. A imigração e a crise do Brasil agrário. São Paulo: Pioneira, 1973.

MONSMA, Karl. Desrespeito e violência: fazendeiros de café e trabalhadores negros no Oeste paulista, 1887-1914. Revista anos 90, Porto Alegre, v. 12, no 21/22, p. 103-149, jan./dez. 2005(a).

MONSMA, Karl; TRUZZI, Oswaldo; BOAS, Silvia Keller Villas. Entre a paixão e a família: casamentos interétnicos de jovens italianos no Oeste paulista, 1890-1914. In: RADIN, José Carlos (org.). Cultura e Identidade Italiana no Brasil: algumas abordagens. Joaçaba: Editora Unoesc, p. 177-204. 2005(b).

RAGO, Margareth. Do cabaré ao lar: a utopia da cidade disciplinar, Brasil, 18901930. Rio de Janeiro: Paz e Terra, 1985.

SCHWARCZ, Lilia K. Moritz, O espetáculo das raças: cientistas, instituições e questão racial no Brasil, 1870-1930. São Paulo: Companhia das Letras, 1995.

SLENES, Robert W. Senhores e subalternos no Oeste paulista. In: ALENCASTRO, Luiz Felipe. História da vida privada no Brasil 2. Império: a corte e a modernidade nacional. São Paulo: Companhia das letras, p. 233-290. 1997.

SLENES, Robert W. Na senzala, uma flor. Esperanças e recordações na formação da família escrava - Brasil, Sudeste, Século XIX. Rio de Janeiro: Nova Fronteira, 1999.

STEINER, Philippe. A Sociologia Econômica. São Paulo: Atlas, 2006.

STOLCKE, Verena. A família que não é sagrada. Sistema de trabalho e estrutura familiar: o caso das fazendas de café em São Paulo. In: CORRÊA, Mariza. Colcha de retalhos: estudos sobre a família no Brasil. São Paulo: Brasiliense, 1982.

SWEDBERG, Richard. Sociologia econômica: hoje e amanhã. Tempo Social, São Paulo, v. 16, no 2, p. 7-34, nov. 2004.

TILLY, Chris; TILLY, Charles. Capitalist Work and Labor Markets. In: SMELSER, Neil; SWEDBERG, Richard. The Handbook of Economic Sociology, Russel Sage Fundation, p. 283-312, 1994.

TRUZZI, Oswaldo. São Carlos: Café e indústria, 1850-1950. São Carlos: Edufscar, 2000. 
VAINFAS, Ronaldo. Moralidades brasílicas. In: MELLO E SOUSA, Laura de (org.). História da vida privada no Brasil 1. Cotidiano e vida privada na América portuguesa. São Paulo: Companhia das Letras, p. 221-273, 1997.

WISSENBACH, Maria Cristina Cortês. Da escravidão à liberdade: dimensões de uma privacidade possível. In: SEVCENKO, Nicolau. História da vida privada no Brasil 3. República: da Belle Époque à era do Rádio. São Paulo: Companhia das Letras, p. 49-130, 1998.

ZELIZER, Viviana. Dinheiro, poder e sexo. Cadernos Pagu, n. 32, p. 135-157, jan./jun. 2009.

ZELIZER, Viviana. The Purchase of Intimacy. Princeton, Princeton University Press, 2005a.

ZELIZER, Viviana. Intimité et économie. Terrain, n. 45, p. 13-28, 2005 b.

Recebido em: 04/07/2011

Aceite final: 03/10/2011 